\title{
FORMACִÃO DE PROFESSORES DE GEOGRAFIA NO BRASIL, NA ESPANHA E EM PORTUGAL: UMA LEITURA DAS ESTRUTURAS CURRICULARES VIGENTES EM 2013
}

\author{
Rita de Cassia Gromoni Shimizu* \\ Departamento de Geografia (IGCE)/Universidade Estadual Paulista (Unesp), Rio Claro - SP, Brasil \\ João Pedro Pezzato"* \\ Departamento de Educação (IB)/Universidade Estadual Paulista (Unesp), Rio Claro - SP, Brasil
}

RESUMO: Este artigo tem como objetivo discutir as estruturas curriculares de 10 cursos de formação de professores de Geografia em instituições de três nacionalidades: cinco brasileiras, uma por região - sendo que uma delas teve dois campi analisados -; uma da região da Galícia (Espanha); e uma da região do Minho (Portugal). Trata-se de pesquisa de cunho qualitativo, baseada em análise documental (obtida em 2013) e em referenciais teóricos do campo dos estudos curriculares e da formação de professores. O estudo baseou-se na metodologia qualitativa, com análise de conteúdo. A despeito da relevância apontada nas contribuições teóricas do campo da formação de professores, tanto no Brasil, como na Espanha e em Portugal, as iniciativas de interdisciplinaridade, articulação teoria-prática, interação entre a universidade e o campo de estágio, inserção da pesquisa e de tecnologias voltadas ao ensino na formação inicial para a docência apresentaram-se de maneira pontual, não permeando todos os documentos analisados.

Palavras-chave: Currículo. Formação de professores. Geografia.

\section{GEOGRAPHY TEACHER EDUCATION IN BRAZIL, SPAIN AND POTUGAL: READOUT OF THE CURRICULUM FRAMEWORKS PREVAILED IN 2013}

ABSTRACT: This paper aims to discuss the curriculum frameworks of 10 Geography teacher graduation courses and concern institutions of three nationalities, in other words, one institution per Brazilian region, one institution from the Galicia region (Spain), and one institution from the Minho region (Portugal). It concerns a qualitative survey, based on documental analysis (obtained in 2013), and in the theoretical references in the fields of curriculum studies and teacher education. The qualitative methodology,

"Doutora em Geografia pela Universidade Estadual Paulista (Unesp, Rio Claro), tendo realizado Doutorado Sanduíche na Universidade de Santiago de Compostela (USC, Galícia, Espanha), com bolsa PDSE/CAPES. E-mail: < rgromoni@rc.unesp.br >.

"Doutor em Educação pela Universidade de São Paulo (USP). Docente nos Programas de Pós-Graduação em Educação (IB - Unesp, Rio Claro) e em Geografia (IGCE - Unesp, Rio Claro). E-mail: < jpezzato@rc.unesp.br > 
with content analysis, was the methodological option. Despite the relevance pointed in the theoretical contributions of the teacher education field in Brazil, as well as in Spain and Portugal, the interdisciplinary attempts, articulation of theory and practice, interaction between university and internship field, insertion of the survey and technologies towards teaching, in the initial academic teaching education, presented themselves in a precise manner, not permeating all the analyzed documents.

Keywords: Curriculum. Geography. Teacher education.

\section{INTRODUCุÃO}

A tese de doutorado que deu origem a este artigo teve como objetivo efetuar a leitura curricular da formação de professores de Geografia no Brasil, na Espanha e em Portugal, partindo da hipótese de que a construção e a implementação das propostas formativas das licenciaturas em Geografia encontram-se balizadas em concepções regulatórias, ou seja, visando prioritariamente ao controle burocrático.

A partir do referencial teórico utilizado, o objeto de estudo foi composto de uma instituição por região brasileira, uma instituição da região da Galícia (Espanha) e uma instituição da região do Minho (Portugal).

Foram selecionados os cursos das seguintes instituições brasileiras: Universidade Estadual Paulista (Unesp - campi de Rio Claro e de Presidente Prudente) - região Sudeste; Universidade Federal de Santa Catarina (UFSC) - região Sul; Universidade Federal de Goiás (UFG) - região Centro-Oeste; Universidade Federal de Roraima (UFRR) - região Norte; e Universidade Federal de Pernambuco (UFPE) - região Nordeste. Foram selecionadas duas universidades europeias: a Universidade de Santiago de Compostela (USC, Espanha) e a Universidade do Minho (UMinho, Portugal).

No contexto brasileiro, os seis cursos selecionados oferecem duas opções aos ingressantes: licenciatura e bacharelado. A licenciatura, foco da pesquisa, habilita o graduado a exercer a profissão de professor de Geografia para a Educação Básica (Ensino Fundamental e Ensino Médio), enquanto o bacharelado possibilita o credenciamento no Conselho Regional de Engenharia e Agronomia (CREA), assegurando seu registro profissional e sua participação no mercado de trabalho como geógrafo, apto a desenvolver atividades de consultoria, pesquisa e projetos.

No contexto europeu, a estrutura é um pouco diferente, principalmente após o Processo de Bolonha, que desencadeou diversas mudanças no sistema de ensino, conforme se observa no Quadro 1. 
QUADRO 1 - Sistemas de ensino no Brasil, na Espanha e em Portugal

\begin{tabular}{|c|c|c|c|}
\hline IDADE & BRASIL & ESPANHA & PORTUGAL \\
\hline 0 & \multirow{6}{*}{ Educação Infantil } & \multirow{3}{*}{$\begin{array}{l}\text { Educação Infantil } \\
\qquad\left(1^{\circ} \text { Ciclo }\right)\end{array}$} & \\
\hline 1 & & & \\
\hline 2 & & & \\
\hline 3 & & \multirow{3}{*}{$\begin{array}{l}\text { Educação Infantil } \\
\qquad\left(2^{\circ} \text { Ciclo }\right)\end{array}$} & \multirow{3}{*}{ Educação Pré-Escolar } \\
\hline 4 & & & \\
\hline 5 & & & \\
\hline 6 & \multirow{9}{*}{ Ensino Fundamental } & \multirow{6}{*}{ Educação Primária } & \multirow{4}{*}{ Ensino Básico $\left(1^{\circ}\right.$ Ciclo $)$} \\
\hline 7 & & & \\
\hline 8 & & & \\
\hline 9 & & & \\
\hline 10 & & & \multirow{2}{*}{ Ensino Básico $\left(2^{\circ}\right.$ Ciclo $)$} \\
\hline 11 & & & \\
\hline 12 & & \multirow{4}{*}{$\begin{array}{c}\text { Educação Secundária } \\
\text { Obrigatória }\end{array}$} & \multirow{3}{*}{ Ensino Básico ( $3^{\circ}$ Ciclo) } \\
\hline 13 & & & \\
\hline 14 & & & \\
\hline 15 & \multirow{3}{*}{ Ensino Médio } & & \multirow{3}{*}{ Ensino Secundário } \\
\hline 16 & & Bachillerato ou Formação & \\
\hline 17 & & Profissional & \\
\hline 18 & & & Ensino Pós-Secundário \\
\hline
\end{tabular}

Fonte: SHIMIZU, 2015.

Nesse sentido, na Universidade de Santiago de Compostela e na Universidade do Minho, a formação do professor de Geografia passou, em virtude do Processo de Bolonha, a ser realizada no mestrado, após a graduação. Assim, foram analisados os dois cursos de mestrado da USC e da UMinho, uma vez que é nesse nível que ocorrem a formação pedagógica e a certificação profissional para a docência.

Sendo assim, na tese em questão, foram analisados oito cursos de licenciatura em Geografia e dois cursos de mestrado voltados ao ensino de Geografia, a partir de oito projetos político-pedagógicos, 10 estruturas curriculares e 306 planos de ensino das disciplinas obrigatórias dos cursos mencionados. No presente momento, por se tratar de um artigo, serão divulgados os resultados concernentes à análise efetuada das estruturas curriculares. 


\section{REFLEXÕES SOBRE A FORMACุÃO DE PROFESSORES}

Vive-se, nos dias atuais, um contexto de profundas transformações, que implicam em inúmeras mudanças sociais, bem como numa expansão acelerada da tecnologia e dos meios de comunicação. Diante de tantos desafios, da chamada globalização, faz-se necessária, em todas as áreas do conhecimento, uma formação que consiga acompanhar essas demandas e, portanto, ela deve ser permanente e contínua.

No panorama da formação de professores, o cenário não é diferente. Aliás, em se tratando de uma área tão complexa quanto relevante, esse assunto tem sido amplamente discutido e pesquisado, com o consenso de que essa formação não deva ocorrer somente durante a formação inicial, desenvolvendo-se durante toda a vida profissional do docente, pois, conforme destaca Cavalcanti (2006, p. 121), "os cursos de formação inicial representam uma intervenção muito débil das concepções do aluno, se comparada com a influência que eles têm em toda sua vida escolar".

No entanto, não se pode negar a importância da formação inicial e a necessidade de constantes reflexões a respeito de como essa formação ocorre no âmbito das universidades, pois, conforme estabelece o art. 62 da Lei de Diretrizes e Bases da Educação Nacional (LDB), "a formação de docentes para atuar na educação básica far-se-á em nível superior, em curso de licenciatura, de graduação plena, em universidades e institutos superiores de educação" (BRASIL, 1996).

No Brasil, para atuar no Ensino Fundamental ou Médio, há essa exigência da LDB, enquanto que, para atuar no Ensino Superior, exigese a formação em nível de pós-graduação (mestrado e doutorado). Já, no contexto europeu, a formação no chamado $1^{\circ}$ ciclo (licenciatura) possui duração mínima de três anos (180 a 240 ECTS - European Credit Transfer and Accumulation System, ou Sistema Europeu de Transferência e Acumulação de Créditos), confere o grau de licenciado e é totalmente voltada a atender às exigências do mercado de trabalho. Dessa forma, a estrutura curricular é composta na sua totalidade de disciplinas específicas de Geografia, sem foco à área pedagógica, pois esse é o objetivo da formação no $2^{\circ}$ ciclo (máster), com duração de um a dois anos (60 a 120 ECTS), devendo totalizar 300 ECTS para concluir o $2^{\circ}$ ciclo, conforme previsto na legislação:

Para atuar no ensino de educação secundária obrigatória e de bachilleratto será necessário possuir o título de Licenciado, Engenheiro ou Arquiteto, ou o título de graduação equivalente, além da formação pedagógica e didática em nível de pósgraduação. (ESPANHA, 2006, art. 94, tradução nossa) ${ }^{1}$ 
Outro aspecto a ser considerado é que, numa análise dos diversos períodos históricos, percebe-se a existência de dois modelos de formação que Saviani (2009, p. 148-149), ao fazer um estudo específico do caso brasileiro, define da seguinte maneira:

a) modelo dos conteúdos culturais-cognitivos: para este modelo, a formação do professor se esgota na cultura geral e no domínio específico dos conteúdos da área de conhecimento correspondente à disciplina que irá lecionar;

b) modelo pedagógico-didático: contrapondo-se ao anterior, este modelo considera que a formação do professor propriamente dita só se completa com o efetivo preparo pedagógico-didático.

Embora, em determinados momentos, tentou-se articular esses dois modelos, mesmo que timidamente nas legislações, o que se percebe é que, na prática, a implantação ou a formalização dessas mudanças sempre valorizou um modelo em detrimento de outro; e, na maioria das vezes, essa valorização sempre esteve atrelada ao modelo dos conteúdos culturais-cognitivos, conforme destacado por Saviani (2009).

Essa desvalorização do modelo pedagógico-didático da formação de professores, também se constitui num problema não resolvido na Espanha e em Portugal, conforme destacam os seguintes artigos:

No entanto, não se deve esquecer que ainda persiste em muitos alunos e professores da própria universidade a idéia de que a melhor formação do futuro professor deve se basear em uma formação consistente em Ciências Sociais, e não em Didática das Ciências Sociais, acrescida de práticas docentes em um centro de ensino. (MUÑOZ, 1997, p. 108, tradução nossa) ${ }^{2}$

A experiência de várias décadas de formação de professores em Portugal e a investigação educacional (tanto no nosso país como no estrangeiro) mostram que esta formação não se pode reduzir à sua dimensão académica (aprendizagem de conteúdos organizados por disciplinas), mas tem de integrar uma componente prática e reflexiva. (ALARCÃO et al., 1997, p. 8)

Isso pode indicar que a opinião dos pesquisadores brasileiros e europeus é convergente quanto à preocupação com o aspecto pedagógico-didático, no que concerne à necessidade de integração dos conhecimentos, reconhecida como fundamental para a formação de professores.

Porém, mesmo reconhecendo a necessidade de integração dos dois modelos, o dilema está em como promover a articulação, no caso da formação de professores, dessas dimensões, com vistas a uma formação com qualidade, pois, segundo Alarcão et al. (1997, p. 9), a competência do professor "não se constrói por justaposição, mas por integração entre o saber académico, o saber prático e o saber transversal”. Além disso, apesar das diversas mudanças legais 
em que persistem a falta de articulação entre teoria e prática e entre pesquisa e ensino, em geral "os conteúdos pedagógicos são atribuídos às disciplinas de conteúdo específico sem articulação com as dos conteúdos da ciência de referência" (PEZZATO, 2012, p. 35).

Nesse aspecto, torna-se primordial destacar o que Cunha (2006, p. 496) sempre vem apresentando em suas pesquisas sobre inovações curriculares, ou seja, que mesmo se confirmando a necessidade de articulação entre teoria e prática, nos currículos a teoria sempre precede a prática e assume condição superior sobre aquela, assumindo que:

[...] o conhecimento válido é apenas o que passou pelo crivo do método científico, a modernidade supervalorizou a teoria e passou a ideia de que ela seria o referente da prática. Essa lógica preside, predominantemente, os currículos escolares e universitários e o conceito de formação acadêmica.

Relacionado a isso, há outro aspecto amplamente discutido nas pesquisas nacionais e internacionais que diz respeito à estrutura fortemente disciplinar dos currículos, e isso não ocorre de maneira diferente no currículo de formação de professores.

Fala-se muito da necessidade de se romper com o modelo disciplinar, ou seja, aquele que contempla a organização das disciplinas na forma de grades curriculares, sem que haja relação entre aquelas e estas. Na maioria das vezes, são de responsabilidade de departamentos diferentes que, por sua vez, quase nunca se relacionam. No entanto, o modelo que prevalece nos currículos pode ser o mesmo, conforme descrito por Moreira (2001, p. 60), ou seja:

[...] a dispersão encontrada no conjunto de disciplinas pelas quais os departamentos se responsabilizam deve dificultar a reunião de pesquisadores e de estudantes em torno do estudo de temas relevantes, impedindo, consequentemente, o desenvolvimento de projetos mais densos e significativos.

Há que se pontuar também que as legislações preveem, mesmo que timidamente, a inserção da pesquisa na formação de professores, e, entre os estudiosos dessa área, tanto nacionais como internacionais, é consenso o importante papel da pesquisa no ensino, como forma de o professor produzir conhecimento, com o consequente aprimoramento de sua prática e desenvolvimento profissional.

No caso brasileiro, o artigo $3^{\circ}$ das Diretrizes Curriculares Nacionais (DCN) (BRASIL, 2002a) prevê que a formação de professores deva contemplar a articulação teoria-prática e a inserção da prática, considerando: "III - a pesquisa, com foco no processo de ensino e de aprendizagem, uma vez que ensinar requer, tanto dispor de conhecimentos e mobilizá-los para a ação, como compreender 
o processo de construção do conhecimento". Nesse contexto, Pontuschka, Paganelli e Cacete (2009, p. 94-95) destacam que:

[...] particularmente as DCN, indicam que um dos problemas a ser enfrentado nos cursos de licenciatura se refere ao tratamento dispensado à pesquisa. [...] A ideia é ressaltar a importância da pesquisa na construção de uma atitude cotidiana de compreensão dos processos de aprendizagem e desenvolvimento dos alunos e de busca de autonomia na interpretação da realidade.

Paoli (1998), Cunha (1996, 2013), Tardif (2005) e Severino (2008) também são contundentes ao discorrer sobre esse tema em artigos de épocas distintas, destacando que a indissociabilidade entre ensino e pesquisa deve ser o critério básico para o reconhecimento do status universitário e, portanto, deve orientar a estrutura e a organização das instituições educacionais de nível superior.

Porém, conforme salientam André (2006) e Pontuschka, Paganelli e Cacete (2009), quando se pretende inserir a pesquisa na formação de professores, ficam visíveis as carências concernentes às habilidades de análise, de interpretação dos dados coletados e, sobretudo, a capacidade de elaboração de textos e documentos. Esses problemas estão presentes, porque, conforme destacam Pontuschka, Paganelli e Cacete (2009, p. 97):

É comum ouvir que amiúde os alunos chegam ao ensino superior apresentando um nível baixo de conhecimento e com inúmeras dificuldades, entre as quais a falta de domínio da língua para, por exemplo, analisar, interpretar e redigir textos.

Ainda segundo esses autores, essa falta de domínio da língua interfere em todas as atividades, de maneira geral, chegando a levar os alunos a uma atitude de desânimo perante os estudos, pois as atividades escolares, geralmente, envolvem pesquisas, trabalhos escritos e seminários, que sempre dependem das ações de ler, interpretar e analisar textos e documentos. Isso se confirma, ainda, nas palavras de Khaoule e Souza (2013, p. 94), quando afirmam que outras barreiras enfrentadas pelos alunos em formação "também se vinculam à dificuldade de compreensão da linguagem dos textos acadêmicos, da erudição dos autores e da descontextualização dos conteúdos".

Christofoletti (1997), em artigo sobre as perspectivas para a organização curricular no ensino de Geografia, separa as disciplinas em quatro conjuntos: núcleo básico, disciplinas complementares, disciplinas de formação metodológica e disciplinas de formação técnica. Nesse último grupo, o autor destaca a necessidade de domínio das linguagens verbal, matemática e informatizada, pois, em sua opinião, ao lado da produção do conhecimento, há a necessidade 
de se promover o ensino e a difusão dos resultados obtidos. Ele ainda acrescenta que "não se deve desprezar o arsenal disponível em outras línguas ocidentais, tais como em francês, alemão, espanhol e italiano" (CHRISTOFOLETTT, 1997, p. 13).

Os autores Dionísio, Pereira e Viseu (2011) destacam a "presença ausente" da leitura e da escrita nos currículos e acrescentam que se torna imprescindível, em muitos países europeus, que a formação (também inicial) de professores de todas as disciplinas, seja capaz de proporcionar conhecimento e recursos didáticos sobre os processos de leitura e escrita.

Outra dimensão a ser analisada na formação de professores diz respeito à possibilidade de se ter acesso à formação que inclua as tecnologias, com vistas a atender às demandas do contexto atual, e isso está previsto nos incisos VI dos artigos $2^{\circ}$ e $7^{\circ}$ das DCN (BRASIL, 2002a):

Art. $2^{\circ}$ : [...] VI - o uso de tecnologias da informação e da comunicação e de metodologias, estratégias e materiais de apoio inovadores; [...].

Art. $7^{\circ}:[\ldots]$ VI - as escolas de formação garantirão, com qualidade e quantidade, recursos pedagógicos como biblioteca, laboratórios, videoteca, entre outros, além de recursos de tecnologias da informação e da comunicação.

Contudo, a inserção das tecnologias na formação de professores implica em importantes transformações culturais que exigem postura de adaptação dos docentes, conforme descreve Cunha (2006, p. 491):

A ampliação e democratização do acesso às novas tecnologias vêm afetando o estatuto do saber e, consequentemente, propondo importantes transformações culturais. Provocam necessidades que culminam num refazer de relações que professores e alunos estabelecem com o conhecimento. [...] Não resistem nem concorrem com as tecnologias.

É conveniente destacar que todas essas reflexões apresentadas sobre a formação de professores se aplicam também à formação de professores de Geografia. Entretanto, torna-se necessário fazer algumas considerações relacionadas às características específicas dessa área.

Inicialmente, os conhecimentos geográficos foram considerados de suma importância para a construção da nacionalidade, tendo a disciplina o objetivo de disseminar o patriotismo. Além disso, possui característica que a distingue das outras disciplinas, ou seja, antes de se consolidar como área de ensino ou pesquisa em nível superior, ela já era disciplina obrigatória nos currículos do ensino primário e secundário. Isso significa dizer que a Geografia ensinada nas escolas era de responsabilidade de professores que não possuíam 
formação na área, e a formação de professores de Geografia, em nível universitário, só teve início em 1934 com a implantação do curso de Geografia na Universidade de São Paulo (USP).

É preciso considerar, ainda, uma das dificuldades na formação inicial de professores de Geografia, segundo Cavalcanti (2006, p. 116):

[...] para a formulação de seu trabalho docente, as referências mais diretas são, de um lado, os conhecimentos geográficos acadêmicos, tanto a Geografia acadêmica quanto a didática da Geografia e, de outro, a própria Geografia escolar já constituída. Sabe-se que a Geografia que se ensina nas escolas de educação básica, ou seja, a Geografia escolar, não é a mesma que se ensina e que se investiga na Universidade.

Esse distanciamento existente entre a Geografia das universidades e a Geografia das escolas tem trazido sérias implicações para as práticas docentes, uma vez que falta ao futuro professor embasamento que sustente a sua prática em sala de aula. Nas palavras de Cavalcanti (2006), os avanços da Geografia científica são importantes referências para a construção da Geografia escolar, mas são insuficientes para a formação do professor.

Para Krahe e Franco (2005, p. 274), esse distanciamento se deve, entre outras coisas, ao fato de que o professor da especialidade "ignora o que se desenrola nas aulas das pedagógicas e vice-versa, ocasionando uma formação fragmentada, quando deveria ser no mínimo de complementaridade, ainda que o ideal fosse o de integralidade".

Também, conforme destacam Steinke e Carvalho (2013), faz-se necessário o fortalecimento dos conteúdos estruturantes do conhecimento geográfico, sem os quais se inviabiliza o processo formativo no ensino básico, uma vez que, em qualquer situação didáticopedagógica, o professor terá que dispor dos elementos conceituais que fundamentam a ciência geográfica, mas, na licenciatura, "muito mais que oferecer disciplinas didático-pedagógicas, é preciso preparar o futuro docente para atuar na docência do ensino básico de Geografia" (STEINKE; CARVALHO, 2013, p. 83).

Para Lestegás (2002, p. 184, tradução nossa), uma das alternativas para superar esse distanciamento é entender que a Geografia escolar não é mera tradução da Geografia científica, ou seja:

Aceitar que a geografia escolar não é a tradução simplificada de uma geografia científica, mas uma criação particular e original da escola que atenda aos objetivos sociais que são específicos, é uma das condições básicas que podem permitir um ensino renovado da geografia a serviço da problematização do conhecimento e da construção da aprendizagem significativos, funcionais e, além disso, úteis aos alunos. ${ }^{3}$

Há um consenso entre os pesquisadores de que a fragmentação do conhecimento geográfico é importante para o aprofundamento 
do conhecimento, mas também contribui para o distanciamento entre a Geografia acadêmica e a Geografia escolar. Para Pontuschka, Paganelli e Cacete (2009, p. 161):

Além da dicotomia entre geógrafos físicos e geógrafos humanos, há no interior dessas "duas geografias" aqueles que se aprofundam no conhecimento da climatologia, da geomorfologia, da geografia urbana, da geografia agrária, etc. [...] Essa fragmentação é importante porque se faz o recorte para aprofundar o conhecimento em determinada área, mas não pode ser tomada como parâmetro para o ensino fundamental e médio.

Silva (2008, p. 218) afirma que muitas são as críticas à fragmentação das Ciências Humanas e atribui a isso o corporativismo epistemológico, no qual:

[...] cada departamento ou área de saber se emancipa das demandas sociais tanto quanto da relação com outras áreas afins ou não e, do mesmo modo, dentro de um só curso, cada disciplina defende suas fronteiras; é abordada e estudada separadamente em relação às outras.

Entretanto, esses autores destacam que a Geografia, devido às suas múltiplas dimensões como área de conhecimento, possui grandes possibilidades para inserir a interdisciplinaridade no ensino universitário e a transversalidade no Ensino Básico. Na universidade, vai depender de "atitude interdisciplinar" do professor-pesquisador, pois, ao selecionar e disponibilizar os conteúdos, métodos e técnicas trabalhados em sua disciplina, poderá contribuir com um objeto de estudo em interação com os professores das demais disciplinas. No Ensino Básico, poderá contribuir com os temas transversais (Pluralidade Cultural, Meio Ambiente, Saúde e Temas Locais), conforme o planejamento das escolas. Contudo, para Silva (2008), assumir essa atitude interdisciplinar é o grande entrave que ocorre na universidade, onde prevalecem as "vaidades intelectuais, narcisismos, interesses políticos, ostracismos e dificuldades materiais ou psicológicas de todo tipo" (SILVA, 2008, p. 222). Portanto, em sua opinião, "mais que romper com uma dispersão de conteúdos, é importante romper com a dispersão/isolamento entre os indivíduos" (SILVA, 2008, p. 223).

Outra questão sempre em discussão nas pesquisas sobre formação de professores de Geografia diz respeito à falta de identidade da licenciatura, tendo em vista que, apesar das modalidades de bacharelado e licenciatura apresentarem estruturas separadas, acaba prevalecendo a estrutura do bacharelado, e as disciplinas são ministradas conjuntamente para alunos das duas modalidades, ignorando-se as diferenças de necessidade. 
Pontuschka, Paganellie Cacete (2009, p. 91-93) afirmam entender como positivo o processo de elaboração das DCN, principalmente no que concerne ao fato de a licenciatura ter conquistado "terminalidade e integralidade", conforme se observa no texto a seguir:

Na universidade pública, bacharelado e licenciatura têm-se constituído, no decurso
da história, como cursos separados, com pouca ou nenhuma relação entre si.
Nesse caso, a licenciatura aparece numa situação de inferioridade, ou seja, o curso
técnico-científico ganha maior importância, enquanto a licenciatura caracteriza-se
como um curso complementar e secundário. [...] Assim, o processo de elaboração
das DCN para os cursos de graduação consolidou o direcionamento da formação
para três categorias de carreiras: bacharelado acadêmico, bacharelado profissional
e licenciatura. Nesse sentido, a licenciatura ganhou terminalidade e integralidade
próprias em relação ao bacharelado, constituindo, portanto, um projeto específico,
com um currículo próprio que não se deve confundir com o bacharelado ou com
o modelo antigo que ficou caracterizado como "modelo 3+1".

Estando envolvido com a área geográfica, Christofoletti (1997, p. 17) antecipou-se, numa "previsão" de futuro, quando apresentou suas preocupações quanto aos critérios para a organização da estrutura curricular no ensino de Geografia. A partir de sua reflexão a respeito da estrutura conceitual da Geografia e da natureza de seu objeto, o autor apresentou suas propostas para a licenciatura e o bacharelado, enfatizando a necessidade de se ter uma estrutura diferenciada para cada modalidade, tendo em vista, que essa separação seria de fundamental importância no futuro. De acordo com suas palavras:

Na organização curricular deve-se esclarecer se o contexto é para o bacharelado ou para a licenciatura. [...] Essa distinção é fundamental, não tanto para o elenco nominativo das disciplinas curriculares, mas para a dosagem e composição do conteúdo programático a ser ministrado. Embora na atualidade os cursos de graduação em Geografia ofereçam a mesclagem desses dois direcionamentos, dentro em breve surgirá a necessidade de uma separação estrutural e funcional, sem empecilhos para que o interessado possa circular e absorver a potencialidade de ambas as estruturas. (CHRISTOFOLETTI, 1997, p. 17, grifo nosso)

Cinco anos após a publicação do artigo de Christofoletti (1997), o artigo $7^{\circ}$ das DCN (Resolução CNE/CP n $\left.{ }^{\circ} 1 / 2002\right)$ passa a estabelecer que:

Art. $7^{\circ} \mathrm{A}$ organização institucional da formação dos professores, a serviço do desenvolvimento de competências, levará em conta que:

I - a formação deverá ser realizada em processo autônomo, em curso de licenciatura plena, numa estrutura com identidade própria. (BRASIL, 2002b)

Embora esteja prevista na legislação essa estrutura com identidade própria, na prática isso ainda não se consolidou. Pezzato 
(2012, p. 24), ao discorrer sobre o panorama da formação de professores de Geografia no contexto brasileiro, num resumo sobre as legislações brasileiras, acrescenta que elas:

[...] explicitam a necessidade de rompimento da concepção linear da organização curricular dos cursos de licenciatura, apontam para a necessidade da promoção de maior flexibilidade na organização curricular dos cursos do ensino superior. Contudo, entre o discurso e a prática há grande diferença.

E é nesse contexto que o presente artigo se insere, ou seja, busca identificar: como estão organizadas as estruturas curriculares dos cursos selecionados; como estão distribuídos os conteúdos referentes ao conhecimento específico da Geografia e da docência; se é possível identificar algum tipo de articulação entre teoria e prática; se há a inserção da pesquisa; e se as estruturas contemplam a introdução de novas tecnologias ou possibilitam o domínio das linguagens.

\section{ANÁLISE E INTERPRETAC̣̃̃O DOS DADOS}

Tendo em vista a natureza dos dados, optou-se por pesquisa qualitativa, segundo Bogdan e Biklen (1999) e André e Ludke (1986), utilizando-se de entrevistas, análise documental e análise de conteúdo, segundo Bardin (2009).

Partindo-se dos referenciais teóricos, iniciou-se a análise documental, ou seja, após a definição das universidades que fariam parte do contexto da pesquisa, buscou-se efetuar o levantamento das informações em seus sites, com vistas a obter as informações que estivessem disponíveis.

No que concerne às instituições, no caso da USC, a trajetória para formação é a licenciatura em Xeografia e Ordenación do Territorio (4 anos) e o Máster Universitario en Profesorado de Educación Secundaria Obligatoria (2 anos). Já na UMinho a trajetória para formação é a licenciatura em Geografia e Planeamento (3 anos), 10 ECTS em História e o Mestrado em Ensino de História e Geografia (2 anos).

As estruturas curriculares analisadas referem-se àquelas vigentes em 2013, e foram acessadas no site dos cursos ou, ainda, quando necessário, foram consultados os Projetos Político-Pedagógicos (PPP) dos cursos brasileiros, a Memória e o Dossiê dos cursos europeus.

Durante a análise, buscou-se entender como estão organizadas as estruturas curriculares dos cursos, e o primeiro ponto observado é aquele sobre a existência de um modelo disciplinar com visível separação entre os conteúdos específicos de Geografia e os conteúdos pedagógicos, conforme destacado por Saviani (2009). E, a partir disso, 
procurou-se identificar o "peso" dos núcleos que compõem as estruturas curriculares, bem como as disciplinas que compõem as estruturas.

\section{Núcleos que compõem a estrutura curricular}

Adotando a categorização elaborada por Pezzato (2012), e também levando em consideração as orientações contidas nas DCN para o curso de graduação em Geografia (BRASIL, 2001) ${ }^{4}$ sobre a organização dos conteúdos curriculares básicos e complementares da licenciatura em Geografia em cinco núcleos, foram utilizadas as tabelas disponíveis em Shimizu (2015), que apresentam separadamente as estruturas curriculares dos cursos da UFRR, UFPE, UFSC, Unesp/ RC, Unesp/PP, UFG, USC e UMinho com as respectivas cargas horárias $(\mathrm{CH})$, bem como as porcentagens de carga horária de cada disciplina $(\%)$ em relação ao total.

As tabelas a seguir apresentam, de forma sintetizada, as cargas horárias de todos os cursos (Tabela 1), bem como as respectivas porcentagens (Tabela 2), visando facilitar a visualização das informações e possibilitar a análise.

TABELA 1 - Carga horária total das estruturas curriculares dos cursos analisados, vigentes em 2013

\begin{tabular}{|c|c|c|c|c|c|c|c|c|c|c|}
\hline \multirow{2}{*}{ NC } & \multirow{2}{*}{ UFRR } & \multirow{2}{*}{ UFPE } & \multirow{2}{*}{ UFSC } & \multirow{2}{*}{$\begin{array}{c}\text { Unesp } \\
\text { RC }\end{array}$} & \multirow{2}{*}{$\begin{array}{c}\text { Unesp } \\
\text { PP }\end{array}$} & \multirow{2}{*}{ UFG } & \multicolumn{2}{|c|}{ USC } & \multicolumn{2}{|c|}{ UMinho } \\
\hline & & & & & & & Licenc. & Máster & Licenc. & Mestrado \\
\hline EBG & 1.410 & 1.020 & 1.548 & 1.260 & 1.140 & 896 & 1.296 & & 1.680 & \\
\hline ECG & 510 & 120 & 306 & 360 & 360 & 384 & 240 & & 240 & \\
\hline ETL & 600 & 780 & 576 & 360 & 360 & 512 & & 294 & & 585 \\
\hline EST & 300 & 390 & 414 & 420 & 405 & 416 & & 200 & & 415 \\
\hline TCC & 60 & 90 & & & & 128 & 72 & 150 & & \\
\hline $\mathrm{OL}$ & & 300 & 216 & 240 & 360 & 320 & 288 & & 240 & 45 \\
\hline AC & & 200 & 200 & 210 & 200 & 200 & & & & \\
\hline TOT & 2.880 & 2.900 & 3.260 & 2.850 & 2.825 & 2.856 & & & & 205 \\
\hline
\end{tabular}

$\mathrm{NC}$ = núcleos dos conteúdos; $\mathrm{EBG}$ = conteúdos específicos básicos para a Geografia; ECG = conteúdos específicos complementares para a Geografia; ETL = conteúdos específicos teóricos para a licenciatura; EST = estágios; TCC = trabalho de conclusão de curso; $\mathrm{OL}=$ opções livres; $\mathrm{AC}=$ atividades complementares.

Fonte: SHIMIZU (2015). 
TABELA 2 - Porcentagem dos conteúdos na carga horária total dos cursos analisados, vigentes em 2013

\begin{tabular}{|c|c|c|c|c|c|c|c|c|}
\hline CONTEÚDOS & UFRR & UFPE & UFSC & $\begin{array}{l}\text { Unesp } \\
\text { RC }\end{array}$ & $\begin{array}{l}\text { Unesp } \\
\text { PP }\end{array}$ & UFG & USC & UMinho \\
\hline $\begin{array}{l}\text { Específicos para a } \\
\text { Geografia (EBG +ECG) }\end{array}$ & $66,67 \%$ & $39,31 \%$ & $56,87 \%$ & $56,84 \%$ & $53,10 \%$ & $44,82 \%$ & $60,47 \%$ & $59,91 \%$ \\
\hline $\begin{array}{l}\text { Específicos para a } \\
\text { docência (ETL) }\end{array}$ & $20,83 \%$ & $26,90 \%$ & $17,67 \%$ & $12,63 \%$ & $12,74 \%$ & $17,93 \%$ & $11,57 \%$ & $18,25 \%$ \\
\hline Estágios (EST) & $10,42 \%$ & $13,45 \%$ & $12,70 \%$ & $14,74 \%$ & $14,34 \%$ & $14,57 \%$ & $7,87 \%$ & $12,95 \%$ \\
\hline TCC & $2,08 \%$ & $3,10 \%$ & & & & $4,48 \%$ & $8,74 \%$ & \\
\hline Opções livres & & $10,34 \%$ & $6,63 \%$ & $8,42 \%$ & $12,74 \%$ & $11,21 \%$ & $11,34 \%$ & $8,89 \%$ \\
\hline \multirow[t]{2}{*}{$\begin{array}{l}\text { Atividades } \\
\text { complementares }\end{array}$} & & $6,90 \%$ & $6,13 \%$ & $7,37 \%$ & $7,08 \%$ & $7,00 \%$ & & \\
\hline & $100 \%$ & $100 \%$ & $100 \%$ & $100 \%$ & $100 \%$ & $100 \%$ & $100 \%$ & $100 \%$ \\
\hline
\end{tabular}

Obs.: as porcentagens referentes à USC e à UMinho contemplam os totais da licenciatura e do mestrado.

Fonte: SHIMIZU (2015).

\section{Conhecimentos específicos da Geografia e da docência}

Diante das Tabelas 1 e 2, é possível perceber que, para a maioria dos cursos, prevalece a formação de professores de Geografia a partir dos conhecimentos específicos da Geografia, com índices acima de $50 \%$ de sua carga horária total, oscilando entre 53,10\% (Unesp/PP) e 66,67\% (UFRR). As duas exceções são a UFPE e a UFG com índices inferiores, ou seja, 39,31\% e 44,82\%, respectivamente.

No caso da UFPE, a estrutura é composta por 26,90\% de conhecimentos específicos para a docência, e os estágios, TCC, optativas e AC perfazem um total de $33,79 \%$, o que demonstra, em princípio, certo equilíbrio entre os conhecimentos específicos da área de conhecimento e os conhecimentos relacionados à docência. Porém, como o rol de optativas é composto por 17 disciplinas - das quais nove são relacionadas aos conteúdos específicos de Geografia, e sete, aos conteúdos específicos complementares, e apenas uma relacionada ao conteúdo pedagógico (Avaliação do Livro Didático em Geografia) -, se os $10,34 \%$ de disciplinas optativas forem cumpridas na área de conhecimentos específicos de Geografia, já volta a desequilibrar e a se igualar ao quadro das demais universidades.

No que concerne à UFG, apesar da estrutura contemplar 44,82\% de conhecimentos específicos para a Geografia, os conteúdos específicos para a docência perfazem apenas 17,93\% da carga horária total do curso, 
e 37,36\% do total são relativos aos estágios, TCC, optativas e AC. Isso também demonstra o prevalecimento dos conteúdos específicos sobre os pedagógicos. Além disso, a carga horária de disciplinas optativas a ser cumprida é de $320 \mathrm{~h}$, que correspondem a $11,21 \%$ da carga horária total do curso. Da mesma forma, das 33 disciplinas oferecidas como optativas, 30 referem-se aos conteúdos específicos básicos e complementares da Geografia, e apenas três estão relacionadas aos conteúdos pedagógicos (Cultura, Currículo e Avaliação; Metodologia de Ensino de Geografia III; Psicologia da Educação II).

Uma vez que a maioria das disciplinas optativas possui caráter de formação específica de Geografia, pode-se concluir que a parte curricular que propicia o desenvolvimento de habilidades profissionais voltadas à atuação nas escolas e nas salas de aula fica bem reduzida, conforme também já havia sido observado nas pesquisas sobre os cursos de Pedagogia (GATTI; NUNES, 2009).

Pontuschka, Paganelli e Cacete (2009) destacaram que, no decorrer da história da universidade pública, bacharelado e licenciatura constituem-se como cursos separados, com pouca ou nenhuma relação entre si e que a licenciatura sempre aparece numa situação de inferioridade, caracterizando-se como curso complementar e secundário.

\section{Estágios e atividades complementares}

A carga horária dos estágios aparece de maneira equilibrada entre os cursos brasileiros, muito provavelmente para atender à exigência legal, variando de 10,42\% (UFRR) a 14,74\% (Unesp/RC), e varia de 300h a (UFRR) a 420h (Unesp/RC).

$\mathrm{Na}$ USC, o estágio ocorre durante o máster, nas disciplinas chamadas Prácticum 1 e Prácticum 2, com carga horária de 200h, acrescidas de $410 \mathrm{~h}$ de trabalho autônomo do aluno, denominado "tutoria". E, na UMinho, a carga horária total do estágio, que ocorre também em nível de mestrado, perfaz total de $1.260 \mathrm{~h}$, sendo $415 \mathrm{~h}$ de "contacto" e 845 h destinadas ao trabalho autônomo do aluno, incluindo a redação do relatório.

$\mathrm{Na}$ USC e na UMinho não estão previstas atividades extras e/ou complementares nas estruturas curriculares, pois elas já contemplam alta carga horária de trabalho autônomo dos alunos.

No Brasil, as atividades complementares foram regulamentadas por meio do Parecer CNE/CES no 492/2001 (BRASIL, 2001) e da Resolução CNE/CP no 2 (BRASIL, 2002b), que estabelecem 200h para outras formas de atividades acadêmicas, científicas e culturais. 
Na UFRR, a Resolução n 4/2012-CEPE/UFRR dispõe sobre as atividades complementares e prevê que elas devem propiciar o aproveitamento dos

[...] conhecimentos adquiridos pelo discente, dentro ou fora do ambiente acadêmico, através de estudos e práticas independentes presenciais e/ou a distância, com a finalidade de enriquecer o processo de ensino-aprendizagem, privilegiando a complementação da formação social e profissional. (UFRR, 2012, p. 1)

Além disso, em seu parágrafo único, determina que a carga horária de atividades complementares a ser cumprida pelo discente no curso "é aquela estabelecida no seu PPP, cabendo ao Conselho de Curso/Núcleo Docente Estruturante estabelecê-la quando o mesmo se mostrar omisso" (UFRR, 2012, p. 1).

Embora o PPP do curso tenha sido aprovado em 2014, portanto, posterior à data da resolução de 2012, não contempla tal informação e, no item referente a esse assunto, consta apenas que:

Os alunos do curso de Geografia terão contato com atividades de pesquisa científica a partir de participação no projeto de pesquisa dos professores do curso, na forma de bolsas de iniciação científica (PICI, PIBIC) na qual terão contato com novas metodologias, com a rotina do trabalho cientifico, participação de salões, simpósios e congressos apresentando trabalhos e tendo contato com pesquisadores de áreas afins. (UFRR, 2014, p. 27)

Porém, o referido documento não apresenta a carga horária destinada às atividades complementares e nem a forma como elas serão consideradas.

Nas demais universidades brasileiras, a carga horária destinada às atividades complementares corresponde entre 4,71\% (UFSC) e 7,37\% (Unesp/RC) da carga horária total do curso. Conforme pôde ser observado na Tabela 1 , todas contemplam as $200 \mathrm{~h}$ estipuladas pela legislação.

Na USC, o artigo 12.8 do Real Decreto ${ }^{\circ}$ 1.393/2007 estabelece que podem também ser reconhecidos, no máximo, 6 ECTS em outras atividades:

De acordo com o artigo 46.2.i) da Lei Orgânica 6/2001 de 21 de dezembro das universidades, os alunos poderão obter reconhecimento acadêmico em créditos pela participação em atividades culturais, desportivas, de representação estudantil, voluntariado e de cooperação até um máximo de 6 créditos do total estrutura curricular cursada. (ESPANHA, 2007, p. 44.040, tradução nossa) ${ }^{5}$

Na USC, o reconhecimento dos créditos de tais atividades está vinculado à participação dos estudantes nos órgãos colegiados, atividades desportivas da universidade (incluindo alunos com alto rendimento em 
Jogos Olímpicos, campeonatos, etc.), atividades culturais da universidade (teatro, coral, grupo de dança, etc.) e também atividades de voluntariado. No ano letivo 2013-2014, em torno de 200 alunos realizavam serviço voluntário nas entidades, e, segundo a responsável pela Oficina de Voluntariado: "o serviço voluntário é uma forma de preparação para o trabalho e as empresas valorizam essas atividades".

Em síntese, ao se fazer paralelo com a pesquisa realizada por Gatti e Nunes (2009) sobre os cursos de Pedagogia, nesse caso também fica pouco claro o que seriam as "atividades complementares", na maioria dos cursos analisados.

\section{Trabalhos de conclusão de curso (TCC)}

A carga horária destinada ao TCC varia entre 2,08\% (UFRR) e $8,74 \%$ (USC), o equivalente a $60 \mathrm{~h}$ e $150 \mathrm{~h}$, respectivamente.

Tanto na UFSC como na Unesp/RC, Unesp/PP e UMinho, não há a obrigatoriedade de TCC para a licenciatura, o que novamente registra o distanciamento existente entre ensino e pesquisa nos cursos de formação de professores. E, nesse aspecto, conforme destaca Pezzato (2012, p. 36):

A ação profissional de um professor que tem a experiência da pesquisa e passa a compreender-se como produtor de conhecimento, e não meramente como reprodutor de um conhecimento produzido externamente ao seu âmbito de atuação, pode produzir novos significados para a prática docente.

A valorização da pesquisa no curso de formação de professores pode ser observada nos relatos da entrevista realizada, em janeiro de 2014, com a Coordenadora do Mestrado da UMinho, Profa. Dra. Maria do Céu Melo Esteves Pereira, quando diz que:

E, portanto, nesse estágio, os alunos, além das aulas, têm que, nas suas próprias aulas, fazerer uma espécie de um projeto de investigação em que o modelo é um projeto de investigação-ação [...]. De fato, na nossa universidade, sempre pensamos num professor como investigador pelas suas práticas, defendemos aqui os valores do professor reflexivo, investigador transparente, produtor de pensamento crítico, etc. (Profa. Dra. Maria do Céu Melo Esteves Pereira, 2014)

\section{Opções livres}

A carga horária das disciplinas optativas varia de 216h (UFSC) a $360 \mathrm{~h}$ (Unesp/PP), e representam de 6,35\% (UFSC) a $12,74 \%$ (Unesp/PP) da carga horária total dos cursos. Na Tabela 3, pode ser observado o número de disciplinas optativas que cada curso oferece, segundo a área de conhecimento. 
TABELA 3 - Número de disciplinas optativas vigentes em 2013 nos cursos analisados, segundo a área de conhecimento

\begin{tabular}{|l|c|c|c|c|c|c|c|c|}
\hline CONHECIMENTOS & UFRR & UFPE & UFSC & $\begin{array}{c}\text { Unesp } \\
\text { RC }\end{array}$ & $\begin{array}{c}\text { Unesp } \\
\text { PP }\end{array}$ & UFG & USC & UMinho \\
\hline $\begin{array}{l}\text { Específicos básicos } \\
\text { para a Geografia }\end{array}$ & 2 & 9 & 29 & 23 & 25 & 26 & 10 & 5 \\
\hline $\begin{array}{l}\text { Específicos } \\
\text { complementares para } \\
\text { a Geografia }\end{array}$ & 2 & 7 & 11 & 21 & 6 & 4 & 2 & 6 \\
\hline Subtotal & 4 & 16 & 40 & 44 & 31 & 30 & 12 & 11 \\
\hline $\begin{array}{l}\text { Específicos para a } \\
\text { docência }\end{array}$ & - & 1 & 3 & 5 & 2 & 3 & - & 4 \\
\hline TOTAL & 4 & $\mathbf{1 7}$ & $\mathbf{4 3}$ & $\mathbf{4 9}$ & $\mathbf{3 3}$ & $\mathbf{3 3}$ & $\mathbf{1 2}$ & $\mathbf{1 5}$ \\
\hline
\end{tabular}

Obs.: Os cursos de formação de professores da USC e da UMinho compreendem a graduação e o máster.

Fonte: SHIMIZU, 2015.

É conveniente destacar que a UFRR não especifica em seu PPP ou na estrutura curricular, tampouco nas informações disponíveis no site, a carga horária de disciplinas optativas a ser cumprida para integralização curricular. As informações disponíveis no PPP são a carga horária total do curso, de $2.880 \mathrm{~h}$, conforme distribuição apresentada na Tabela 1, e o rol de quatro disciplinas optativas oferecidas.

Conforme observado na Tabela 3, a UMinho oferece quatro disciplinas optativas relacionadas aos conteúdos específicos para docência, sendo duas delas na licenciatura e duas no mestrado. A USC não oferece optativas no mestrado.

\section{Disciplinas que compõem a estrutura curricular}

Outro aspecto analisado foi a composição das estruturas em todos os cursos. Foram mescladas as 306 disciplinas em análise, e efetuada a classificação por agrupamento (SHIMIZU, 2015).

Considerando uma média de 38 disciplinas por universidade, constatou-se que as estruturas curriculares, tanto as brasileiras como as europeias em questão, possuem basicamente a mesma estrutura - 50\% da composição -, ou seja, 19 disciplinas aparecem em pelo menos cinco das oito universidades em foco, a saber:

Disciplina comum a todas as estruturas: Do total de disciplinas de cada estrutura, 11 são comuns a todos os cursos, ou seja, 9 do conteúdo específico da Geografia e 2 do conteúdo específico da docência: Biogeografia, Cartografia, Climatologia, Geografia Agrária/ Rural, Geologia/Pedologia, Geografia Regional, Geografia Urbana, 
Geomorfologia, as Teorias e Métodos da Geografia, Psicologia da Educação e Políticas Educacionais/Organização Escolar.

Convém destacar que ocorrem diferenças apenas em suas nomenclaturas ou subdivisões, ou seja, no caso da Cartografia, por exemplo, aparecem Cartografia I, II, Básica, Geral, Avançada, Temática, etc. No caso da Climatologia: Climatologia I, Dinâmica, Fundamentos de Climatologia - e, na UMinho, a disciplina intitulada Geografia Física I é aquela que se dedica aos conteúdos da Climatologia, conforme observado em plano de ensino.

Disciplina comum a sete universidades: Duas disciplinas aparecem em sete das oito universidades; isso porque, na estrutura da UFG, não constam disciplinas pertencentes à Geografia Econômica, e, na estrutura da UMinho, não consta a disciplina Didática.

Disciplina comum a seis universidades: Cinco disciplinas aparecem em seis das oito universidades. As disciplinas relativas a Geoprocessamento/Sistemas de Informação Geográfica não constam da estrutura da UFSC e da Unesp/RC; aquelas relativas à Hidrogeografia/Recursos Hídricos não constam nas estruturas da Unesp/PP e da UFG; Geografia da População não consta na Unesp/ RC e na Unesp/PP; Quantificação em Geografia/Estatística não compõem a estrutura da UFPE e da UFSC; e, por último, Teoria Regional/Regionalização não constam na UFPE e na UFG.

Disciplina comum a cinco universidades: Somente uma disciplina aparece em cinco universidades, como é o caso da Geopolítica/ Geografia Política.

Todas essas disciplinas comuns às estruturas já haviam sido incluídas no rol proposto por Christofoletti (1997,p. 10), "apenas como direcionamento global e sem a intenção de ser completo". O autor apresentou uma proposta de estrutura curricular dividida em núcleo básico, núcleo complementar, formação metodológica, formação técnica, além das disciplinas "subsidiárias" e pedagógicas. Destacou, ainda, que "O aspecto mais relevante encontra-se representado pelo conteúdo programático inserido e ministrado nessas disciplinas e não em seu rótulo" (CHRISTOFOLE'TTI, 1997, p. 10).

Entre as demais disciplinas, ocorre considerável diversificação de temas, ou seja, há, pelo menos, 11 disciplinas que aparecem somente em uma universidade, como é o caso de Libras (UFG), Língua Estrangeira (UFRR), Trabalho de Campo Integrado (Unesp/RC), Projeto de Integração Disciplinar (Unesp/PP), Seminários Temáticos (UFRR), História e Memória (UMinho), Cartografia Escolar (UFSC), 
Tecnologia Educativa (UMinho), Fundamentos de Prática de Ensino (Unesp/RC), Aprendizagem e Ensino de História/Geografia e Ciências Sociais (USC) e Avaliação da Aprendizagem (UFPE).

Conforme mencionado, Christofoletti (1997), Dionísio, Pereira e Viseu (2011), e Khaoule e Souza (2013) já enfatizavam a importância do domínio da linguagem, na leitura e na escrita, considerando a necessidade de se promover a difusão dos resultados obtidos na produção de conhecimento. Contudo, ainda se observa essa carência nos cursos analisados.

\section{Inserção das tecnologias nas disciplinas analisadas}

Outro aspecto em análise nos planos de ensino foi a inserção das tecnologias voltadas ao ensino; porém, isso ainda ocorre de maneira muito tímida. Percebe-se que algumas disciplinas utilizam laboratórios de informática em ações pontuais, como, por exemplo, utilização da internet para consulta de censos, acesso a banco de informações, etc. Raras são as disciplinas que abordam aspectos das tecnologias no ensino propriamente dito.

E conveniente destacar que esse aspecto já havia sido mencionado em pesquisa realizada por Pezzato, Shimizu e Russo Cury (2013), quando se constatou a inexpressiva presença de trabalhos relacionados à reflexão sobre as Tecnologias de Informação e Comunicação (TIC) nos trabalhos apresentados no "GT Currículo" (reuniões da Associação Nacional de Pós-Graduação e Pesquisa em Educação - ANPEd - ocorridas no período de 2003 a 2012).

Aspecto nítido nos conteúdos dos planos de ensino é que as disciplinas relacionadas à Cartografia/Geoprocessamento/ Sensoriamento Remoto e à Estatística/Quantificação são as que, de maneira geral, abordam aspectos da tecnologia em seus conteúdos, inclusive com a inserção de ferramentas e softwrares direcionados ao tema.

Além disso, com exceção da UMinho, que possui em sua estrutura curricular a disciplina Tecnologia Educativa, o tema relacionado à informática na educação está presente nas disciplinas Estágio Supervisionado II e III (Unesp/RC), Método e Análise de Material Didático em Geografia (UFRR) e Didática, Currículo e Organização Escolar (USC, máster). Além dessas, a disciplina Sociologia (Unesp/ RC) também aborda o tema referente ao paradigma da tecnologia da informação, voltado às redes interativas e à comunidade eletrônica.

Em face da atual realidade, conforme já apontado por Christofoletti (1997), fica evidente a necessidade de inserção das tecnologias nas estruturas curriculares, de maneira mais contundente, 
com vistas a possibilitar um diálogo entre a formação de professores ocorrida nas universidades e o cenário existente nas escolas.

\section{CONSIDERACְ̃̃ES FINAIS}

A análise indicou certo distanciamento entre o que as pesquisas da área apontam como direcionamento e "mínimo necessário" para a formação de professores e o que de fato prevalece nas instituições analisadas, mesmo levando em consideração as suas distintas realidades.

No que concerne às estruturas curriculares dos cursos de formação de professores de Geografia em estudo, ficou evidente a permanência de modelo fragmentado de conhecimento, fortemente disciplinar e voltado a uma estrutura curricular de especialidades. Assim, fica cada vez mais nítida a dicotomia entre os conteúdos específicos da Geografia e os conteúdos específicos da docência com o prevalecimento da formação de professores de Geografia a partir dos conhecimentos específicos de Geografia, tanto no que concerne às disciplinas obrigatórias como às optativas.

Em geral, os cursos se desenvolvem a partir de um tronco comum, com planos de ensino comuns, disciplinas comuns, estrutura comum ao bacharelado. Tanto que as formações na USC e na UMinho são primeiramente técnicas, e a licenciatura fica caracterizada como especialização profissional. Dessa forma, no geral, fica bem restrita a formação voltada à atuação na docência.

Apesar das raras iniciativas, ainda falta priorizar a formação do professor voltada à Geografia escolar, ou seja, no caso das instituições brasileiras, as disciplinas relacionadas à docência necessitam de eixo norteador às futuras práticas.

Diante da análise das cargas horárias, pode-se afirmar que o bacharelado permanece como prioridade de formação, e a licenciatura se constitui como periferia dos cursos, ficando claro um ponto nevrálgico desses cursos: formar professores não é a prioridade das propostas analisadas.

Apesar das novas diretrizes para o Ensino Superior buscarem apontar a intenção de alterar o formato " $3+1$ ", ou seja, três anos de disciplinas de conteúdo específico e um ano de disciplinas pedagógicas, o que se percebe é que, na maioria dos cursos analisados, a carga horária privilegiada permaneceu. A carga horária das disciplinas específicas chega a ser três vezes maior que a das pedagógicas. Porém, o que muda, por força da legislação em vigor, é a distribuição das disciplinas ao longo do curso, não estando as pedagógicas concentradas no último ano de formação. 
Assim, persiste a concepção dos modelos curriculares anteriores, ou seja, a prioridade é dada à formação técnica, e não à do professor.

Tanto nas instituições brasileiras como nas europeias, com raras e pontuais exceções, a interdisciplinaridade é outro aspecto praticamente inexistente e continua sendo o grande desafio para os cursos em questão. Não se observa, nos documentos analisados, relação entre as disciplinas, sejam elas teóricas/práticas ou específicas / pedagógicas, geralmente, apresentadas de maneira isolada e sem conexão para os alunos, durante o curso.

Entende-se que, na graduação, em especial, nas licenciaturas brasileiras, é primordial uma visão menos fragmentada da realidade, principalmente, no caso de o licenciado optar por seguir a carreira de professor nos Ensinos Fundamental e Médio.

A partir das implicações do Tratado de Bolonha, na Europa, a formação profissional ocorre em dois momentos distintos: primeiro, em nível de graduação, direcionada a uma profissionalização técnica. Em segundo momento, ocorre, em nível de pós-graduação, a formação didático-pedagógica direcionada à docência. Nesse contexto, a articulação entre os conteúdos da ciência de referência com os pedagógicos fica minimizada.

Da mesma forma, a inserção da pesquisa ainda aparece de maneira tímida nesses cursos de formação de professores e, geralmente, caminha dissociada do ensino. Nem todos os cursos utilizam a possibilidade de desenvolvimento do trabalho de conclusão de curso (TCC) na licenciatura, como forma de incentivar e promover a pesquisa. Das universidades analisadas, somente UFG, UFSC e UFPE possuem a disciplina TCC como obrigatória, em um ou dois semestres, demonstrando o interesse em articular ensino e pesquisa na formação inicial.

Na carreira acadêmica das universidades, atualmente, é evidente a valorização cada vez maior da pesquisa em detrimento do ensino, e, mesmo as teorias apontando para a importância da pesquisa articulada ao ensino, não conseguem caminhar juntos de forma a estimular o ensino com pesquisa e proporcionar o "enriquecimento" do trabalho em ambos os sentidos. Nos casos analisados, todos os cursos estão lotados em instituições que possuem programa de pós-graduação, mas, mesmo assim, são raras as iniciativas de projetos que visem articular graduação e pós-graduação.

Apesar de os estágios obrigatórios integrarem as estruturas, raras são as informações a respeito de como e onde eles são realizados ou se há alguma articulação entre universidade e escola.

As atividades complementares aparecem somente nas estruturas brasileiras, conforme determina a legislação, mas, na maioria das 
universidades analisadas, não há especificações quanto à distribuição de carga horária e quanto à forma como elas ocorrem. À exceção desse quadro, encontra-se o PPP da UFSC, que contempla a participação em atividades de pesquisa e sua posterior apresentação no Seminário de Iniciação Científica ou na Semana de Pesquisa e Extensão da UFSC, além da participação em sessão de defesa de doutorado, mestrado ou trabalho de conclusão de curso de graduação como forma de articulação entre ensino-pesquisa e entre graduação-pós-graduação.

Outros três aspectos que merecem olhar mais atento, em face da atual realidade, estão relacionados ao domínio das linguagens e das TIC. O primeiro aspecto refere-se à ausência, nas estruturas, de saberes relacionados à Linguagem Brasileira de Sinais (Libras), que, apesar da determinação das legislações, só consta nas estruturas curriculares da UFPE e da UFG, com 60h e 64h, respectivamente. A UFSC também possui Libras I e Libras II, porém, no rol de optativas do curso, enquanto as demais universidades analisadas não as possuem como obrigatórias ou optativas.

O segundo aspecto diz respeito à importância do domínio da língua portuguesae de umidiomaestrangeiro, pois, emboratambém esteja contemplado na legislação, constata-se, nas universidades brasileiras, que a UFRR é a única que apresenta, em seu núcleo complementar, duas disciplinas obrigatórias em idioma estrangeiro, a escolher entre inglês, francês ou espanhol; e a UFPE, no rol de optativas, possui a disciplina Português Instrumental. Já, nas universidades europeias, para finalização dos cursos, há a exigência de segundo idioma, cuja formação é de responsabilidade das próprias universidades.

O terceiro aspecto está voltado à inserção das tecnologias para o ensino, pois, apesar de constar nos documentos a utilização de laboratórios de informática em ações pontuais ou a abordagem da tecnologia em algumas disciplinas, raras são as que abordam aspectos das tecnologias no ensino propriamente dito. Somente a UMinho possui, em sua estrutura curricular, a disciplina Tecnologia Educativa.

A inserção desses conhecimentos visa possibilitar diálogo entre a formação de professores ocorrida nas universidades e o cenário existente nas escolas. Esse distanciamento, além de causar prejuízo para a formação, não traz contribuição para o ensino.

O quadro exposto demonstra que a integração teoriaprática, a articulação ensino-pesquisa, a interdisciplinaridade e a importância do modelo didático-pedagógico, entre outros aspectos, são as principais demandas para a formação de professores, mas isso também evidencia que muitas mudanças são necessárias para que se consiga chegar a uma formação próxima da ideal. 
Muitas mudanças são necessárias nessa realidade educacional, mas por onde se deve começar? Será que esses cursos estão respondendo às finalidades para as quais foram criados? Não seria conveniente voltar os olhares às políticas públicas de formação de professores? Sabe-se que qualquer mudança nesse sentido envolverá relações de poder, mas também de nada adiantarão reformas que só se voltem a incluir ou excluir disciplinas, mudar seus nomes ou cargas horárias, se não houver processo de reflexão e transformação da essência do curso.

\section{REFERÊNCIAS}

ALARCÃO, Isabel et al. A formação de professores no Portugal de hoje. Documento de Trabalho do CRUP - Conselho de Reitores das Universidades Portuguesas. 1997. 34 p. Disponível em: <www.educ.fc.ul.pt/docentes/jponte/docs-pt/97-Alarcao-Ponte(CRUP). rtf>. Acesso em: 28 out. 2013.

ANDRÉ, Marli E. D. A. Ensinar a pesquisa... Como e para quê? In: SILVA, Aida M. M. et al. (Orgs.). Educação formal e não formal, processos formativos e saberes pedagógicos: desafios para inclusão social. Recife: ENDIPE, 2006. p. 221-233.

ANDRÉ, Marli E. D. A.; LÜDKE, Menga. Pesquisa em Educação: abordagens qualitativas. São Paulo: EPU, 1986. p. 11-52.

BARDIN, Lawrence. Análise de Conteúdo. Lisboa: Edições 70, 2009.

BOGDAN, R. C.; BIKLEN, S. K. Investigação Qualitativa em Educação: uma Introdução à teoria e aos métodos. Portugal: Editora Porto, 1999.

BRASIL. Lei n. 9.394, de 20 de dezembro de 1996. Lei de Diretrizes e Bases da Educação Nacional. Estabelece as diretrizes e bases da educação nacional. Brasília, 1996. Disponível em: <http://www.planalto.gov.br/ccivil_03/leis/L9394.htm>. Acesso em: 20 ago. 2017.

BRASIL. Ministério da Educação. Conselho Nacional de Educação. Parecer CNE/CES n. 492/2001. Diário Oficial da União, seção 1e, p. 50, 9 jul. 2001.

BRASIL. Ministério da Educação. Conselho Nacional de Educação. Resolução CNE/CP n. 1, de 18 de fevereiro de 2002. Institui Diretrizes Curriculares Nacionais para a Formação de Professores da Educação Básica, em nível superior, curso de licenciatura, de graduação plena. Diário Oficial da União, Brasília, seção 1, p. 31, 9 abr. 2002a.

BRASIL. Ministério da Educação. Conselho Nacional de Educação. Resolução CNE/CP n. 2, de 19 de fevereiro de 2002. Institui a duração e a carga horária dos cursos de licenciatura, de graduação plena, de formação de professores da Educação Básica em nível superior. Diário Oficial da União, Brasília, seção 1, p. 9, 4 mar. 2002b.

CAVALCANTI, Lana de S. Geografia escolar na formação e prática docentes: o professor e seu conhecimento geográfico. In: SILVA, Aida M. M. et al. (Orgs.). Educação formal e não formal, processos formativos e saberes pedagógicos: desafios para inclusão social. Recife: ENDIPE, 2006. p. 109-126.

CHRISTOFOLETTI, Antonio. Perspectivas e critérios para a organização da estrutura curricular no ensino da Geografia. Boletim Goiano de Geografia, Goiânia, v. 17, n. 1, p. 1-20, jan./jun. 1997.

CUNHA, Maria I. da. A Didática como Construção: aprendendo com o fazer e pesquisando com o saber. In: SILVA, Aida M. M. et al. (Org.). Educação formal e não formal, processos formativos e saberes pedagógicos: desafios para inclusão social. Recife: ENDIPE, 2006. p. 485-503. 
CUNHA, Maria I. da. Ensino com pesquisa: a prática do professor universitário. Cadernos de Pesquisa, São Paulo, n. 97, p. 31-46, maio 1996.

CUNHA, Maria I. da. Os desafios da qualidade acadêmica e a indissociabilidade do ensino, pesquisa e extensão num contexto de democratização da educação superior. InterCambios, Montevidéu, n. 2, p. 13-21, dez. 2013.

DIONÍSIO, Maria de L. T.; PEREIRA, Maria do C. M. E.; VISEU, Floriano A. V. A leitura e a escrita no currículo: a presença ausente. Atos de Pesquisa em Educação, Blumenau, v. 6, n. 1, p. 94-114, jan./abr. 2011.

ESPANHA. Ley Orgánica 2/2006, de 3 de mayo, de Educación. Disponível em: < https:/ / www.boe.es/boe/dias/2006/05/04/pdfs/A17158-17207.pdf>. Acesso em: 15 out. 2013.

ESPANHA. Real Decreto 1393/2007, de 29 de octubre, por el que se establece la ordenación de las enseñanzas universitarias oficiales. Disponível em: <http://www.boe.es/ boe/dias/2007/10/30/pdfs/A44037-44048.pdf>. Acesso em: 15 out. 2013.

GATTI, Bernadete A.; NUNES, Marina M. R. (Org.) Formação de professores para o Ensino Fundamental: estudo de currículos das Licenciaturas em Pedagogia, Língua Portuguesa, Matemática e Ciências Biológicas. São Paulo: FCC/DPE, 2009. 158 p. (Coleção Textos FCC, 29).

KHAOULE, Anna M. K.; SOUZA, Vanilton C. de. Desafios atuais em relação à formação do professor de Geografia. In: SILVA, Eunice I. da; PIRES, Lucineide M. (Orgs.). Desafios da Didática de Geografia. Goiânia: Ed. da PUC Goiás, 2013. p. 87-105.

KRAHE, Elizabeth D.; FRANCO, Maria E. D. P. Inovações curriculares na formação de professores: em busca de um novo referencial. In: MOREIRA, Jacira C. de; MELLO, Elena M. B.; COSTA, Fátima T. L. da (Org.). Pedagogia Universitária: campo de conhecimento em construção. Cruz Alta: Unicruz, 2005. p. 268-287.

LESTEGÁS, Francisco Rodriguez. Concebir la Geografía Escolar desde una Nueva Perspectiva: una disciplina al servicio de la cultura escolar. Boletin de la A.G.E., Madrid, n. 33, p. 173-186, 2002.

MOREIRA, Antonio F. B. O campo do currículo no Brasil: os anos noventa. In: CANDAU, Vera M. (Org.). Didática, currículo e saberes escolares. 2. ed. Rio de Janeiro: DP\&A, 2001. p. 60-77.

MUÑOZ, Maria I. V. La formación inicial del professorado de Ciencias Sociales de Enseñanza Secundaria: análisis crítico de sus perspectivas y de su realidade. In: FERNÁNDEZ, A. S. (Coord.). La formación del profesorado y la didáctica de las ciencias sociales. Espanha: Diada Editora, 1997. p. 107-115.

PAOLI, Niuvenius J. O princípio da indissociabilidade do ensino e da pesquisa: elementos para uma discussão. Cadernos CEDES, Campinas, n. 22, p. 27-52, 1988.

PEZZATO, João P. Formação docente e Geografia Escolar: um estudo de caso entre Brasil e Espanha. São Paulo: Cultura Acadêmica, 2012. 86 p.

PEZZATO, João P.; SHIMIZU, Rita de C. G.; RUSSO CURY, Iára L. Trends of researches related to curriculum in Brazil in the last 10 years. In: EUROPEAN CONFERENCE ON CURRICULUM STUDIES, 2013, Braga. Anais... Braga: Universidade do Minho, 2013. p. 802-812.

PONTUSCHKA, Nídia N.; PAGANELLI, Tomoko I.; CACETE, Núria H. Para ensinar e aprender Geografia. 3. ed. São Paulo: Cortez, 2009. 383 p.

SAVIANI, Dermeval. Formação de professores: aspectos históricos e teóricos do problema no contexto brasileiro. Revista Brasileira de Educação, Rio de Janeiro, v. 14, n. 40, p. 143 155, jan./abr. 2009.

SEVERINO, Antônio J. Ensino e pesquisa na docência universitária: caminhos para a integração. Cadernos de Pedagogia Universitária, São Paulo, n. 3, p. 7-39, abr. 2008. 
SHIMIZU, Rita de C. Gromoni. Leitura curricular da formação de professores de Geografia: Brasil, Espanha e Portugal. 2015. 184 f. Tese (Doutorado em Geografia) Instituto de Geociências e Ciências Exatas, Universidade Estadual Paulista, Rio Claro, 2015.

SILVA, Sérgio P. Currículo interdisciplinar: resgate da dialética todo-parte. In: MENDONÇA, Marcelo R. Formação continuada, interdisciplinaridade e inclusão social. Catalão: Universidade Federal de Goiás, 2008. p. 215-238.

STEINKE, Valdir A.; CARVALHO, Ane C. A. As dimensões da formação de profissionais em geografia no Brasil: reflexões introdutórias. In: SILVA, Eunice I. da; PIRES, Lucineide M. (Orgs.). Desafios da didática de Geografia. Goiânia: Ed. da PUC Goiás, 2013. p. 69-86.

TARDIF, Maurice. Saberes docentes e formação profissional. 5. ed. Petrópolis: Vozes, 2005. 325 p.

UNIVERSIDADE FEDERAL DE RORAIMA - UFRR. Conselho de Ensino, Pesquisa e Extensão. Resolução n. 14/2012, de 17 de maio de 2012. Dispõe sobre as normas gerais das atividades complementares como componente curricular nos cursos de graduação da UFRR. Boa Vista-RR, 2012. Disponível em: < http://ufrr.br/depgeob/phocadownload/ atividades.pdf>. Acesso em: 15 out. 2013.

UNIVERSIDADE FEDERAL DE RORAIMA - UFRR. Conselho de Ensino, Pesquisa e Extensão. Projeto Político-Pedagógico do curso de Geografia. Boa Vista-RR: UFRR, 2014.

\section{NOTAS}

${ }^{1}$ Para impartir las enseñanzas de educación secundaria obligatoria y de bachillerato será necesario tener el título de Licenciado, Ingeniero o Arquitecto, o el título de Grado equivalente, además de la formación pedagógica y didáctica de nivel de Postgrado. (ESPANHA, 2006, art. 94)

${ }^{2}$ No obstante, no se debe olvidar que todavía persiste en muchos alumnos y profesores de la propia universidad la idea de que la mejor formación del futuro profesorado se debe basar en una formación profunda en Ciencias Sociales, que no en didáctica de las Ciencias Sociales, completada con prácticas docentes en un centro de enseñanza. (MUÑOZ, 1997, p. 108)

${ }^{3}$ Aceptar que la geografía escolar no es la traducción simplificada de una geografía científica, sino una creación particular y original de la escuela que responde a las finalidades sociales que le son propias, es una de las condiciones básicas que pueden posibilitar una didáctica renovada de la geografía al servicio de la problematización del conocimiento y de la construcción de aprendizajes significativos, funcionales y, en suma, útiles por parte de los alumnos.

${ }^{4}$ Parecer CNE/CES no 492/2001.

${ }^{5}$ De acuerdo con artículo 46.2.i.) de la Ley orgánica 6/2001, de 21 de diciembre de universidades, los estudiantes podrán obtener reconocimiento académico en créditos por la participación en actividades universitarias culturales, deportivas, de representación estudiantil, solidarias y de cooperación hasta un máximo de 6 créditos del total del plan de estudios cursados. (ESPANHA, 2007, p. 44.040)

Submetido: 24/05/2016

Aprovado: 29/07/2016

Contato:

Universidade Estadual Paulista (Unesp) Avenida 24-A, 1515 - Bela Vista

Rio Claro|SP|Brasil

CEP 13.506-900 